\title{
A corte, o chá e o voto: 0 consumo como arena política
}

\section{Everardo Rocha}

Doutor; Pontifícia Universidade Católica do Rio de Janeiro

everardo@puc-rio.br

\section{Marina Frid}

Doutoranda; Pontifícia Universidade Católica do Rio de Janeiro

marina_frid@yahoo.com.br

\section{William Corbo}

Doutorando; Pontifícia Universidade Católica do Rio de Janeiro wacorbo@gmail.com

\section{Resumo}

O objetivo deste trabalho é examinar alguns dos mecanismos que articulam o fenômeno do consumo com a busca pelo poder e a atividade política em questões relacionadas ao caráter simbólico dos bens, a certas formas de comércio e às novas sociabilidades propiciadas pelos espaços de compra. Para tanto, serão analisadas três experiências históricas que representam de modo emblemático as relações entre consumo e política: $A$ primeira trata das sociedades de corte dos reinados de Elizabeth I, na Inglaterra, e de Luís XIV, na França. A segunda, do boicote conhecido como a Festa do Chá de Boston, ocorrido durante a Revolução Americana. A terceira experiência analisa a parceria entre grandes magazines e sufragistas na luta pelos direitos femininos do início do século XX. Dessa forma, é possível mostrar alguns dos modos pelos quais, no mundo moderno, as representações e práticas de consumo se configuraram como arenas de expressão política.

\section{Palavras-chave}

Consumo e política. História cultural do consumo. Comunicação, poder e consumo. Representações do consumo. Cultura e consumo.

\section{Introdução}

O trabalho visa analisar determinados contextos históricos nos quais o fenômeno do consumo tornou-se uma arena privilegiada de disputas de poder e expressão política. Investiga, especificamente, três momentos do processo de formação da modernidade, ocorridos 
na Europa e nos Estados Unidos entre os séculos XVI e XX, nos quais o consumo foi utilizado como código e suporte efetivo para a participação política e luta pelo poder. Vamos, portanto, examinar como o caráter simbólico dos bens, certas formas de comércio e sociabilidades geradas em espaços de compra proporcionaram mecanismos de articulação entre o sistema classificatório do consumo e as reivindicações de direitos, prestígio e relações de força da política. 0 objetivo é demonstrar as diferentes maneiras pelas quais as representações, práticas e espaços de consumo se traduziram em estratégias políticas, disputas por prestígio e contestações ideológicas. Os momentos que tomamos como emblemáticos dessa relação ente consumo e atividade política são: primeiro, a sociedade de corte dos reinados de Elizabeth I, na Inglaterra, e de Luís XIV, na França, período no qual o consumo foi utilizado como instrumento de centralização do poder e mecanismo de governo. Segundo, a chamada Festa do Chá de Boston, no princípio da Revolução Americana, quando os colonos boicotaram o chá importado da Inglaterra e fizeram da recusa ao consumo uma forma de posicionamento político-revolucionário. E terceiro, a parceria entre o movimento das sufragistas e os grandes magazines nos principais centros europeus e norte-americanos no início do século XX.

Estudos recentes analisaram as relações entre consumo e política, com foco tanto nas questões da globalização, multiculturalismo e cidadania no final do século XX (CANCLINI, 2008) quanto nas noções de consumo sustentável (PORTILHO, 2005) e ético (FONTENELLE, 2006), e na associação entre publicidade e mobilização juvenil na atualidade (MACHADO, 2011). Este trabalho, porém, tem por diferencial explorar a aproximação entre o consumo e a esfera política através da comparação entre contextos históricos do mundo moderno. É evidente que o fenômeno do consumo envolve muitas questões complexas, devido à extrema centralidade que exerce em nossa experiência social. Seu estudo, portanto, demanda pesquisas sistemáticas para que haja uma compreensão consistente dos significados que incorpora e das formas que assume, tanto no imaginário quanto nas práticas coletivas. 0 consumo perpassa a vida contemporânea com uma força inquestionável; estrutura relações, elabora identidades, modela estilos de vida e constrói mapas culturais que viabilizam modos de convivência em grupo. 0 que vamos mostrar aqui é que, à parte disso, ele também foi, em determinados contextos históricos, uma importante plataforma para atuação de grupos sociais em suas lutas e demandas de espaços de poder.

Há nas ciências sociais um paradoxo em relação ao consumo, pois, apesar de sua extrema relevância, este não é um tema recorrente nas preocupações de sociólogos, antropólogos, historiadores ou cientistas políticos. Dois impasses, ao menos, parecem obstruir a 
reflexão sobre o consumo nas ciências sociais. Um deles é o fato de que incide sobre o consumo uma série de certezas de senso comum; como todos consomem, sentem-se aptos a dar opiniões e justificativas, a julgar, fazer críticas e expressar como se sentem. Todavia, esse não é um problema inaugurado com o consumo. Freud relatava que uma de suas dificuldades durante consolidação do campo psicanalítico resultava justamente do fato de que, por conta dos processos mentais serem inerentes a todos nós, acreditarmos saber muito sobre questões ligadas ao psiquismo (GAY, 1989). 0 mesmo se deu com relação à cultura, que por ser compartilhada em sociedade acaba assumindo significados distintos da "teoria da cultura" pensada pelos antropólogos (DAMATTA, 1986), como arte, conhecimento ou saber. Nesse mesmo sentido, Umberto Eco (2008) mostrou que a indústria cultural foi congestionada por visões ideológicas e emocionais de "apocalípticos" e "integrados", dificultando assim a construção de teorias mais profundas e consistentes. Também no caso do consumo, tanto na mídia quanto no senso comum, existe um moralismo que congestiona a interpretação, ao responsabilizá-lo pelas mazelas de nossa vida social. Um simples olhar sobre os discursos cotidianos evidencia como ele, via de regra, é culpado pelo individualismo exagerado, a ganância sem escrúpulos, a violência urbana, os desequilíbrios familiar, mental e ecológico, e outros que tais. Essa "visão moralista" do consumo está em discursos simplistas e ingênuos, ou até mesmo, com menos frequência, em análises intelectualmente sofisticadas. Falar mal do consumo é banal e culpá-lo pelos problemas que enfrentamos consiste em uma prática bem vista (ROCHA, 2005).

Um outro impasse significativo, que emperra essa reflexão nas ciências sociais, é a evidente diferença ideológica entre produção e consumo que, ente outras coisas, define pesadas distinções na classificação das pessoas e grupos. Quando se diz que alguém é extremamente produtivo, dedicado, ou até mesmo workaholic, viciado em trabalho, soa como um elogio. Inversamente, dizer que uma pessoa é consumista ou gastadora tem valor pejorativo. Assim, há uma superioridade moral da produção e das questões relativas a ela - empresa, profissão, trabalho - quando comparadas com o consumo e as suas questões - preferências, marcas, compras. A produção, como na fábula da cigarra e da formiga, parece oferecer um verdadeiro sentido para a vida, enquanto que, na outra ponta, o consumo é visto como fútil, superficial, falso e impulsivo - no limite, um vício ou doença.

Além de sua superioridade ideológica, a produção ocupa uma categoria explicativa central na pesquisa da modernidade, o que contribuiu para o silêncio das ciências sociais acerca do consumo. Estudos, reflexões e teorias de importantes pensadores enfatizaram 
fortemente a esfera da produção e seus temas vinculados - transformações técnicas, conflitos de classes, desenvolvimento das forças produtivas -, conferindo-lhe o privilégio de ser ponto de partida no entendimento da Revolução Industrial, e, através dela, do nosso mundo (SMITH, 1983; RICARDO, 1982; ENGELS, 2008; MARX, 2008). Nessa démarche, a cultura, a sociedade e a política deveriam ser mero efeito da produção - efeito da esfera econômica enfim - de onde derivariam todas as relações sociais por ela determinadas. Apenas a partir da segunda metade do século XX, o consumo passa a ter algum destaque no campo das ciências sociais e ser interpretado como um fenômeno fundamental na estrutura da sociedade moderno-contemporânea.

Assim como diz Sahlins (1979, p.188), "Sem consumo, o objeto não se completa como um produto: uma casa desocupada não é uma casa.". De fato, produção e consumo são esferas opostas e complementares, duas faces de uma mesma moeda. 0 consumo é um fenômeno coletivo, um sistema que concebe vínculos recíprocos entre bens e pessoas, dentro de um jogo de diferenças, oposições e hierarquizações. Nesse sentido, modela uma rede de comunicação, onde todos e cada um desses bens de consumo carregam significados diferentes conforme o arranjo do sistema. Bens têm usos sociais; criam muros e pontes que tanto incluem e aproximam quanto excluem e afastam (DOUGLAS; ISHERWOOD, 2004). Em suma, o consumo é um lugar de expressão social que surge no bojo da formação do mundo moderno e se configura como uma esfera de representação coletiva, construção de identidades, exposição de estilos de vida e, como veremos a seguir, como uma arena de atuação política.

Analisaremos, portanto, três diferentes acontecimentos históricos nos quais o consumo articula importantes relações com a política. 0 primeiro deles trata das sociedades de corte dos reinados de Elizabeth I e Luís XIV, com especial atenção para a forma com que, em ambos os casos, o dispêndio com a cultura material serviu como mecanismo para centralização do poder e como estratégia de governo. Esse período da história europeia mostra, dentre outras coisas, que mesmo antes da consolidação de um sistema de consumo, a posse e os usos de determinados bens já eram importantes no jogo de poder das sociedades de corte (ELIAS, 2001; MCCRACKEN, 2003; FALCON; RODRIGUES, 2006). Em seguida, examinaremos a Revolução Americana e os boicotes aos produtos ingleses, que aconteceram nas últimas décadas do século XVIII, especialmente o caso da Festa do Chá de Boston, quando os colonos americanos perceberam que a recusa ao consumo configurava um caminho de atuação política frente às medidas de taxação de importação e restrição de comércio, impostas pelo Império Britânico (BREEN, 1988). 0 terceiro acontecimento examina, no início do século XX, a 
parceria entre grandes magazines e sufragistas. Por um lado, os grandes magazines abriram espaço para a mobilização e expressão das reivindicações das militantes, por outro, agiram, naquele contexto, para associar as atividades de consumo ao universo feminino (LEACH, 1984; MILLER 1981). Em todos esses contextos, guardadas as suas singularidades, o consumo constitui um eixo de disputa de poder e uma arena privilegiada para a atuação política.

\section{Os gastos, as sociedades de corte e a centralização do poder}

Na transição para a modernidade, vários acontecimentos foram de extrema relevância na consolidação de uma nova estrutura econômica e social, ancorada, especialmente, na interdependência entre produção e consumo. No clássico estudo de Weber (2007), os dogmas, os valores e as práticas introduzidas pelo protestantismo ascético foram fundamentais tanto para superar resquícios do feudalismo, quanto no processo de transformar transações comerciais, que ocorreriam desde sempre, em um sistema que faz da geração de riquezas um fim em si mesmo - o que Weber (2007) chama de capitalismo moderno. Ao emergir durante o Renascimento, a doutrina protestante estabeleceu um paradigma ético que entende o trabalho como meio de aproximar o divino ao humano, ao passo que este estaria ligado à concepção do ser humano como uma criatura sagrada (FALCON;RODRIGUES, 2006). Para Weber (2007), os ideais protestantes sustentaram ideologicamente a expansão da produção e dos mercados, regidos por princípios capitalistas, como o lucro e a acumulação, ao subverter certos valores culturais, suprimir ocasiões de descanso e contemplação, exaltar um modo de vida parcimonioso e legitimar as atividades produtivas como forma de louvar a Deus.

A industrialização, e a consequente expansão dos meios de produção, aumentam de forma significativa a cultura material disponível. Porém, mais do que isso, desde o início da modernidade, os objetos se desprendem da fixidez de posições tradicionais, e se tornam disponíveis para qualquer pessoa com capacidade pecuniária para adquiri-los. Na vida social da Idade Média, trocas e usos da cultura material estavam atrelados, principalmente, às posições ocupadas pelos atores sociais. Em geral, pode-se dizer que havia um forte vínculo entre os objetos e o status daqueles que os possuíam, como se para um dado lugar social correspondesse determinado conjunto de coisas. Membros da nobreza, por exemplo, partilhavam de um arranjo semelhante de objetos, distintos daqueles apropriados ao clero ou aos camponeses. Vemos isso, sobretudo, em relação às armas, algumas cores, materiais, tecidos, ou ainda determinados costumes e práticas, como, por exemplo, comissionar retratos da 
família (JARDINE, 1998; FRIEDLANDER, 2011). As leis sumptuárias que resistiram na Europa até o século XIX (SENNETT, 1988) também exemplificam essas restrições e limites.

No entanto, já no limiar do mundo moderno, formas incipientes de consumo e moda surgem dentro da própria estrutura tradicional das monarquias britânica e francesa, respectivamente nos séculos XVI e XVII. No reinado de Elizabeth I, entre 1558 e 1603, tal como no de Luís XIV, entre 1643 e 1715, a incitação ao dispêndio por parte dos nobres foi um mecanismo efetivo de centralização do poder e estabilidade política (MCCRACKEN, 2003; WILLIAMS, 1982). Em que pesem as diferenças de contexto, os dois monarcas estimularam a competição de gastos entre membros da nobreza ao fomentar uma vida social intensa em suas cortes, repletas de cerimônias, códigos de indumentária e regras de etiqueta em permanente atualização. Dessa forma, instigavam a competição de gastos entre nobres, aumentavam a dependência deles em relação às Coroas e garantiam, com isso, seu poder absoluto.

Elizabeth Tudor ascendeu ao trono em condições bastante instáveis, com seu domínio ameaçado tanto por forças internas quanto externas. Por isso, o incentivo a participação ativa da nobreza nas atividades da corte foi uma das suas estratégias na administração das tensões de governo e na manutenção de sua posição central no poder. Os senhores e suas famílias eram regularmente convocados a Londres, e a presença simultânea de todos nas cerimônias reais incitava as disputas pela atenção e privilégios da rainha. Como era fundamental permanecer próximo a Elizabeth I, os nobres precisavam deixar suas propriedades por longos períodos e sustentar nova moradia em Londres, com todas as despesas que isso acarretava. A realeza estabeleceu padrões de hospitalidade, decoração e arquitetura, que demandavam reformas e ampliações das residências. Aumentaram os gastos com hospedagem, serviçais, presentes, e, particularmente, roupas alinhadas aos códigos, sempre atualizados pela monarca. De fato, os nobres não apenas precisavam arcar uma série de custeios próprios, como também financiavam as necessidades cerimoniais ainda maiores da rainha. Deste modo, Elizabeth estabeleceu um nível de consumo antes impensável na tradição da monarquia inglesa (MCCRACKEN, 2003; STRONG, 1973).

De modo semelhante, o reinado de Luís XIV é definido, por Norbert Elias (2001), como uma típica sociedade de corte, na qual os bens intermediavam o relacionamento entre o rei e os nobres, que precisavam, com frequência, fazerem-se presentes em Versalhes. A competição entre pares tornou mandatória a proximidade com a realeza e, consequentemente, o consumo conspícuo na manutenção de status e disputa por prestígio. Os membros da nobreza precisavam seguir as normas de etiqueta, expressivas e majestosas instauradas pelo "Rei 
Sol"; gastavam consigo, com suas famílias e comitivas, verdadeiras fortunas com vestimentas adequadas, mobiliário, jardinagem, carruagens, banquetes e joias. A aristocracia francesa despendia com abundância, e Luís XIV, bem lembrado por suas extravagâncias, transformou os nobres que o cercavam em pródigos consumidores, sempre ávidos por se manter em dia com os caprichos do rei (WILLIAMS, 1982).

Esses monarcas introduziram um sistema de etiquetas, modas e elegância necessário para uma sociedade que experimentava o paradoxo de fixar distâncias sociais em espaços onde, muitas vezes, o público e o privado se misturavam. Nas sociedades de corte, o ser social identificava-se com a representação que lhe era conferida, já que a realidade de uma posição dada é exatamente aquilo que a opinião acreditava que ela fosse. A hierarquia era afirmada na submissão política e simbólica, pois a lógica da corte funcionava através de uma distinção pela dependência, por sua vez caracterizada pelo respeito à etiqueta estabelecida pela realeza (FALCON;RODRIGUES, 2006).

As convenções e regras de elegância, típicas dessas sociedades de corte, impuseram um consumo exacerbado, uma exibição na qual todos os nobres competiam constantemente pelas contribuições, regalias e títulos da realeza. Como uma espécie de potlatch ${ }^{1}$, os aristocratas se viam impelidos a gastar, cada vez mais, com moda e luxos a fim de reivindicar seu status na hierarquia do reino. A indução aos gastos por parte daqueles que poderiam desafiar o poder foi estratégia para a dominação política. Paulatinamente, o dispêndio, cada vez maior, para experimentar a distinção, enfraqueceu as casas nobres naquelas cortes, o que consistiu em um fator importante no processo de formação do Estado moderno. Ao se deslocar de suas terras, realizar despesas exorbitantes e acentuar seus níveis de endividamento, o aristocrata teve seu poder esvaziado e aumentou consideravelmente sua subordinação econômica e social ao monarca. McCraken (2003) observa que, nesse processo, a nobreza redirecionou suas prioridades de gasto do coletivo - a sustentação da tradição familiar, da herança e do poder dentro de suas comunidades - para o individual: as demandas imediatas na manutenção de sua própria condição prestigiosa dentro das sociedades de corte. Ao invés da conservação do patrimônio, tornaram-se mandatórias as despesas cada vez maiores para acompanhar os sistemas de moda estabelecidos por Elizabeth I e por Luís XIV. Ao fim e ao cabo, as duas experiências fizeram do consumo um dispositivo de poder no jogo centralizador do Estado, e uma importante arena de participação social e encenação política.

1 Potlatch é um ritual de algumas sociedades tribais no qual a lógica é que para aumentar a projeção social do seu grupo de referência, o doador realiza um dispêndio cada vez maior de riquezas com a intenção de, no limite, tornar impossível a retribuição. 0 potlatch é exaustivamente analisado no clássico trabalho de Marcel Mauss (1974), Ensaio sobre a dádiva, de 1924. 


\section{0 não consumir, a independência e a revolução}

Ainda durante seu reinado, Elizabeth concedeu à conhecida Companhia Britânica das Índias Orientais (então chamada de Governor and Company of Merchants of London trading into the East Indies), o privilégio de monopólio dos negócios com o Oriente. Tratava-se de uma associação de mercadores e aristocratas que, durante quase 300 anos, dominou as rotas de comércio orientais, particularmente com a exploração das especiarias e mercadorias que obtinham na China e na Índia. Em meados do século XVIII, as colônias britânicas na América do Norte estavam entre os principais destinos desse intenso fluxo de comércio, importando quantidades cada vez maiores da extensa gama de artigos - tecidos, móveis, tapetes, tipos de papel, luvas, cerâmicas, chás, entre outros. Para Breen (1988), o nascimento de uma "sociedade de consumo" anglo-americana ocorre, justamente nesse período, com a acentuada ampliação da variedade de bens disponíveis. Nesse sentido, sugere uma abordagem sobre o desenrolar da Revolução Americana - que compreende o período entre 1765 e 1783 - que parte da questão do consumo, ao analisar como sucessivas tentativas de boicote aos produtos ingleses foram fundamentais na formação de uma consciência patriótica entre os colonos.

A ocupação do território estadunidense ocorreu de forma dispersa, e, no século XVIII, grupos provenientes de diversas origens étnicas e filiações religiosas povoavam a região. Não havia, portanto, um senso de unidade entre as colônias, que viviam de maneira quase alheia umas às outras. Em suma, a característica que possuíam em comum era o consumo dos produtos enviados pela Inglaterra (BREEN, 1988). Para entender o que levou os colonos a rejeitarem os produtos importados como forma de posicionamento político, cabe recapitular alguns acontecimentos decisivos que precederam a deflagração do processo revolucionário. Com o resultado das Guerras Franco-Indígenas, ou Guerra dos Sete Anos, em 1763, o Império Britânico passou por uma alteração significativa em sua abrangência colonizadora. Os ingleses assumiram o controle de toda a América do Norte, incluindo o Canadá, antes dominado pelos franceses. A Coroa dava relativa autonomia às colônias norte-americanas, porém mantendo a subordinação desta, sobretudo, por meio de decisões relacionadas às atividades comerciais. Os altos custos da guerra deixaram o Império com uma dívida que atingia o valor de 130 milhões de libras e, com ela, a necessidade de um aumento na receita originária das colônias. A partir daí, sucessivas medidas foram tomadas para cobrir os débitos e garantir os custos de manutenção do território norte-americano. 
De fato, a vitória na Guerra dos Sete Anos despertou um sentimento incipiente de independência entre os colonos norte-americanos, que perceberam que tinham recursos para controlar suas fronteiras e já não tanto do poderio militar britânico. Essa confiança na capacidade interna foi um fator importante para as mobilizações que se sucederam até a Guerra de Independência. Em 1764, a Coroa decreta a Lei do Açúcar, que combatia seu contrabando e garantia receitas para o governo britânico, ao instituir taxas para a importação de produtos de luxo vindos da Europa, como vinho, linho e seda, e restringir a exportação de mercadorias, como pele e couro, fazendo da Inglaterra a única compradora das colônias. Os colonos protestaram formalmente e promoveram um boicote aos bens importados dos ingleses. A Lei do Selo, de 1765, determinou que todo material impresso, dentre este panfletos, jornais, documentos legais e certificados, deveria levar o selo real comprado através de agentes norte-americanos especificamente nomeados pela Coroa britânica. A reação foi ainda mais contundente: comerciantes das colônias, organizados em grupos chamados de "Filhos da Liberdade", elaboraram novos protestos; agentes que vendiam os selos foram agredidos, assim como autoridades inglesas, que tiveram suas casas e locais de trabalho atacados. Mais adiante, em 1767, as Leis Townshend, determinaram, entre outras coisas, o aumento das taxas alfandegárias para uma série de artigos ingleses importados pelos americanos - chá, tecido, tinta, papel, chumbo, etc. Os boicotes às mercadorias inglesas foram intensos e acabaram por reduzir drasticamente a importação, especialmente do chá, um dos produtos mais consumidos nas casas dos colonos. Se os "Filhos da Liberdade" se engajavam contra a importação em protestos violentos, as "Filhas da Liberdade" reuniam-se em torno de um movimento, conhecido como "spinningbees", para tecer as roupas da população, fabricar artigos caseiros de uso cotidiano e, com isso, cessar o consumo de bens importados. A Coroa reagiu com sua força militar, e deslocou milhares de soldados para Boston e Nova Iorque. Após confrontos sangrentos, o governo britânico finalmente revogou as Leis Townshend em 1770. Manteve, no entanto, o imposto exclusivamente sobre o chá, especiaria que, poucos anos depois, se tornaria centro de um embate político marcante para a história dos Estados Unidos (DRIVER, 2006).

A princípio, a anulação parcial das Leis Townshend foi suficiente para apaziguar as relações entre os colonos e o governo britânico. Os boicotes cessaram e o chá, bem como outros produtos, tornou a ser abundantemente importado pelos locais. Porém, a situação financeira da Companhia Britânica se deteriorava, e medidas precisavam ser tomadas para reverter os prejuízos. Em especial, no final de 1772, havia um enorme excedente de esto- 
ques de chá que ameaçava saturar o mercado doméstico britânico. Para conter as perdas da Companhia, em maio de 1773, o Parlamento inglês passa a Lei do Chá com o consentimento do Rei George III. Dentre outras coisas, a lei conferia à Companhia, pela primeira vez, plena autonomia na exportação do chá para as colônias norte-americanas. Uma nova onda de protestos culminou em um movimento amplo de boicote contra o chá importado, que passou a ser devolvido aos ingleses. No episódio conhecido como Festa do Chá de Boston, em 16 de dezembro de 1773, um grupo de "Filhos da Liberdade" disfarçados de guerreiros Mohawak2, embarcou nos navios britânicos e jogou ao mar centenas de arcas repletas de folhas de chá trazidas da Inglaterra. Essa manifestação foi vista como um ato de grande desrespeito à Coroa e ao Parlamento, que, em 1774, reagiu impondo uma série de leis coercitivas para, além de ressarcir as mercadorias perdidas, aplicar controle total sobre os colonos. Por sua vez, os norte-americanos, cada vez mais dispostos a romper com o Império, responderam no mesmo ano com a realização do Primeiro Congresso Continental, na Filadélfia (Driver, 2006). 0 episódio da Festa do Chá de Boston não foi isolado, mas constituiu a principal mobilização que antecedeu a Guerra de Independência, entre 1775 e 17833.

Durante os primeiros anos da Revolução Americana, os boicotes dos colonos aos artigos importados da Inglaterra, não só combateram as medidas restritivas e taxativas da Coroa, como também fortaleceram o processo de independência a partir de um sentimento de unidade ancorado no consumo, ou melhor, na recusa do mesmo. Os artigos, importados de maneira massiva, se tornaram o elo que faltava entre as diferentes colônias, um código comum que interligou unidades antes dispersas e alheias umas às outras. Isso só veio à tona quando grupos de norte-americanos, cada vez mais descontentes com a dependência em relação ao Império, especialmente devido às medidas de taxação comercial, começaram a aprender que "(...) padrões de consumo ofereciam uma linguagem efetiva de protesto político." (BREEN, 1988, p.90). 0 debate incitado pelo boicote aos produtos importados - sobretudo do chá, a bebida mais difundida nas casas dos colonos - levou homens e mulheres comuns a pensarem questões ideológicas a partir de suas práticas de compras. 0 consumo ou a ausência do consumo de uma determinada mercadoria, passou a representar, naquele contexto, o posicionamento dos indivíduos sobre a questão, mais ampla, da relação entre os Estados Unidos e a Inglaterra (BREEN, 1988). Se, por um lado, a rejeição aos bens ingleses

${ }^{2}$ Os Mohawk são um conhecido grupo indígena norte-americano.

${ }^{3}$ Atualmente, a "festa do chá" nomeia a ala mais conservadora do partido republicano, o Tea Party. 
contribuiu na formação de uma coesão entre os colonos, por outro, estabeleceu o corte diferencial destes frente àqueles que os subjugavam.

Em resumo, o sentimento de unidade nacional começava a se formar entre os habitantes das colônias ao longo dos quase vinte anos compreendidos pela Revolução Americana, e o fenômeno do consumo foi um dos alicerces fundamentais desse aprendizado. A rejeição aos bens importados funcionou como discurso político através do qual os colonos conseguiram vislumbrar um projeto coletivo, primeiro, de pertencimento a uma nova unidade e, em seguida, de emancipação. Naquele momento, consumir chá deixou de ser uma atividade íntima, e passou a simbolizar o rompimento com a autoridade do Império Britânico. A independência dos Estados Unidos foi um processo gradual, bastante complexo, e os boicotes foram importantes iniciativas anteriores à deflagração da Guerra. A atitude consciente de negar o consumo se tornou um meio poderoso de expressão política e uma espécie de código do patriotismo entre os colonos, homens e mulheres, durante os anos da Revolução. Estudos recentes abordam a apropriação do discurso patriótico pela publicidade como uma forma de dialogar com consumidores (GHILANI, 2012), e os limites e possibilidades de engajamento juvenil, nos dias de hoje, através da recusa ao consumo de bens (PORTWOODSTACER, 2012). Aqui, observamos como o desenvolvimento da nação que, desde o século $\mathrm{XX}$, está entre as grandes protagonistas do comércio internacional e que, no limite, representa um ícone da "sociedade de consumo", começou com a experiência da negação do consumo como forma de linguagem política.

\section{0 voto, as mulheres e os grandes magazines}

A partir da segunda metade do século XIX, uma nova modalidade de comércio surge nas principais cidades europeias e norte-americanas. Por suas inúmeras inovações em técnicas de vendas e estratégias de comunicação, a eclosão dos grandes magazines pode ser considerada uma etapa decisiva na consolidação do sistema de consumo moderno (LEACH, 1984; MILLER, 1981; MCCRAKEN, 2003; ROCHA; FRID; CORBO, 2014). A combinação de diversos fatores favoreceu o surgimento do novo modelo de negócios, que tinha a ousada proposta de reunir a totalidade de bens de consumo disponíveis em gigantescos espaços de compras. É nesse contexto que a autonomização do consumo se concretiza plenamente e se estabelece, de forma mais nítida, como um fenômeno social e uma esfera paralela e complementar à produção (MCCRAKEN, 2003). Os majestosos empreendimentos surgiram em locais como Paris, Nova Iorque, Filadélfia e Chicago, a partir dos anos de 1850, em meio a 
uma conjunção de forças, dentre as quais podemos destacar: o estímulo aos gastos com o romantismo e a formação de um mercado de enciclopédias, novelas sentimentais, jornais e leituras em geral, desde a segunda metade do século XVIII (CAMPBELL, 2001; DARNTON, 1996); a expansão da imprensa e da publicidade; a reestruturação dos centros urbanos; o crescimento da burguesia; e, como nos interessa mais de perto aqui, as transformações do lugar social da mulher (DABHOIWALA, 2013; LEACH, 1984; SENNETT, 1988). Tamanho foi o impacto dessas lojas para a vida social da época, que Émile Zola (2008), clássico escritor francês, dedicou um romance inteiro ao que chamou de "catedrais do comércio moderno" (ROCHA; FRID; CORBO, 2014).

Os grandes magazines ofereciam, aos seus clientes, uma extensão do estilo de vida burguês, e estimulavam as atividades de compras pela exposição de produtos, em vitrines e prateleiras ao alcance das mãos, exibição dos preços em etiquetas, calendários de eventos e promoções regulares, decoração requintada e arquitetura grandiosa. Além de inúmeras seções com toda sorte de bens - tecidos, sedas, mantôs, echarpes, luvas, bibelôs, móveis, bebidas alcoólicas, guarda-chuvas, brinquedos, flores, etc. -, as lojas tinham restaurantes, bistrôs, salas de descanso e até bibliotecas para o encanto dos consumidores (LEACH, 1984). Podese dizer que os padrões e técnicas comuns aos centros comerciais de hoje foram todos originalmente reunidos, se não inventados, pelos grandes magazines, entre a segunda metade do século XIX e início do XX. A lógica financeira das lojas era baseada na venda em grandes quantidades, com margens de lucro reduzidas. 0 objetivo era vender muito e rápido, acelerar o fluxo de receitas e renovar constantemente os estoques.

Uma das transformações centrais, originada nos grandes magazines, relacionava-se ao recrutamento de um público dominantemente feminino. Eles foram, na época, um espaço no qual as mulheres podiam circular sozinhas, fazer compras para a casa e para a família, encontrar as amigas e ocupar suas tardes. Os mercados e pequenos comércios que predominavam até a primeira metade do século XIX eram dispersos e frequentados por classes inferiores; inadequados, portanto, aos ambientes ideais para a circulação da mulher burguesa. Além de pouco convenientes e nada confortáveis, deixavam a mulher muito exposta ao fazê-la percorrer vielas atrás dos pontos de venda especializados em cada produto, sujeita aos riscos da rua e ao assédio masculino (SENNETT, 1988; DABHOIWALA, 2013). Nesse sentido, um diferencial fundamental do projeto das lojas de departamentos consistia em reunir os mais diversos artigos em um mesmo local fechado, seguro e belo, que se tornava próprio e acolhedor para as mulheres burguesas ao reproduzir certas características dos ambientes 
domésticos e religiosos, nos quais elas tradicionalmente circulavam. Esses empreendimentos praticaram inúmeras inovações especificamente para atrair e agradar suas consumidoras: desde instalar elevadores e oferecer banheiros públicos - o primeiro na França, por exemplo, foi construído no Bon Marché (MILLER, 1981) - até distribuir brindes - bolas, doces e figurinhas para as crianças que acompanhavam suas mães nas compras. Os grandes magazines posicionaram a mulher no centro do sistema de consumo, tanto como principal responsável pelas atividades de compras, quanto como força de trabalho. As lojas eram uma alternativa de emprego para mulheres pobres, que assim conquistavam alguma independência financeira e, ainda, experimentavam o universo burguês pelo contato cotidiano com a clientela. Também viviam algo dos gostos e práticas burguesas, ao despender seus salários em compras e gastos durante seus dias de folga. Seja como consumidoras ou trabalhadoras, as mulheres foram, em larga medida, responsáveis por modelar uma cultura de consumo na passagem entre os séculos XIX e XX (LEACH, 1984).

0 contexto no qual os grandes magazines surgem e se expandem é também aquele no qual grupos de mulheres começam a se mobilizar nas lutas por direitos e por mais liberdade. Lutas frequentes na França, na Inglaterra e nos Estados Unidos atravessaram o período entre meados do século XIX e início do século XX. Um fato marcante se deu em 1867, quando John Stuart Mill, membro do Parlamento, fez um pronunciamento em defesa da igualdade entre mulheres e homens, tanto no seio familiar quanto na sociedade. 0 parlamentar destacou que as relações entre ambos os sexos, que subordinavam um ao outro em todas as situações, representavam importantes barreiras para o progresso da humanidade, e que deveriam ser substituídas por um sistema de igualdade. Nessa mesma época, reivindicações por direitos civis ganharam ainda mais penetração social com o surgimento do que viria a ser conhecido como feminismo, criado a partir do texto Les Droits de la Femme, escrito em 1869 por León Richier, que organizou um congresso internacional do movimento em 1878 (BEAUVOIR, 1970). Antes, no século XVII, as reivindicações pela liberdade e por direitos femininos partiam de uma pequena vanguarda formada por mulheres da burguesia - sem qualquer poder político e que atuavam através de petições, manifestações e jornais. Porém, entre meados do século XIX e início do XX, as lutas ocorreram abertamente, na própria arena pública das ruas das grandes cidades (ARNAUD-DUC, 1991).

Talvez o movimento mais representativo desse período, chamado de "primeira onda" do feminismo (KROLOKKE;SCOTT, 2006), tenha sido a luta das sufragistas em torno do direito ao voto das mulheres. Nas ruas e manifestações públicas, as militantes da causa com- 
batiam os estereótipos de feminilidade predominantes à época, que, dentre outras coisas, excluíam as mulheres da esfera pública, exclusivamente masculina, e as atrelavam ao lar e à família. De fato, o processo de liberalização e emancipação da mulher é bastante recente, e apenas após a Primeira Guerra Mundial, países das Américas do Sul e Central, Inglaterra, Grécia, Espanha, Itália e Austrália solidificaram um quadro de igualdade de direitos civis entre os sexos. Já França e Suíça, por exemplo, esperaram até meados do século XX para atender essa reivindicação. No século XIX, o direito estava ancorado no princípio do livre arbítrio do indivíduo, entretanto, no caso francês, a mulher era vista como um ser relativamente inferior ao homem, considerado o verdadeiro "sujeito de direito", complementar em seus papeis de mãe, esposa e filha. Alguns juristas argumentavam que as mulheres deveriam ser tratadas de maneira desigual, já que, no fundo, elas ansiavam por ser protegidas contra o mal que poderiam causar para si próprias(ARNAUD-DUC, 1991).

De modo geral, as reivindicações femininas tiveram maior êxito, inicialmente, em países protestantes. Um projeto de reforma jurídica, a Reform Bill, aprovado na Inglaterra em 1832 pode ser considerado ponto de partida da movimentação sufragista (ARNAUD-DUC, 1991). Um avanço significativo da lei foi o emprego do termo "person" - equivalente à pessoa -, ao invés de "male" - equivalente a homem -, para designar os eleitores do voto censitário. No mesmo país, a associação feminina da cidade de Sheffield enviou para a Câmara dos Lordes a primeira petição que clamava pelo sufrágio feminino. Nessa experiência, é novamente fundamental a participação ativa do deputado John Stuart Mill, que, em 1869, publica Subjection of Women, tornando-se a principal referência do movimento feminista. Apesar da rejeição das propostas pelo Parlamento, o impacto das ideias do deputado ocasionaram alguns progressos no cotidiano das mulheres inglesas, que começaram a ocupar mais os espaços públicos e, em localidades pontuais, a avançar em alguns de seus direitos. Entretanto, diante das recusas ao voto feminino em âmbito nacional, as burguesas optaram pela radicalização do movimento e colocaram em prática uma tática violenta através da Women's Social and Political Union, um ativo grupo político e social criado por Mrs. Pankhurst em 1903. A repressão contra as sufragistas foi grande no início do século $\mathrm{XX}$, com destaque para episódios como as frequentes prisões de militantes e os conflitos da chamada Black Friday (nenhuma relação com a festa contemporânea de consumo) de novembro de 1910 (ARNAUDDUC, 1991).

Nesse processo, as mulheres encontraram, particularmente nos grandes magazines, um local diferente das casas e igrejas e adequado para maior participação social. Ao criar um 
ambiente especificamente forjado para a sociabilidade feminina, as lojas de departamentos contribuíram para a inserção das mulheres burguesas, pequeno-burguesas, e até as de condição financeira menos favorecida na esfera pública como consumidoras e trabalhadoras. A entrada nas lojas era livre e lá podiam passar suas horas com certa independência, conversar, compartilhar experiências e conhecer as reivindicações dos movimentos. Era o surgimento de uma solidariedade feminina (LE GOFF;AITKEN, 2011). Quando iniciaram as primeiras mobilizações pelo direito ao voto e à educação, as sufragistas contavam com os espaços, os serviços, o cosmopolitismo e a interação propiciada pelos grandes magazines. As lojas eram lugar de consumo e produção para mulheres de classes distintas, e ofereceram um valioso apoio ao sufrágio feminino.

Em Londres, Paris e diversas cidades dos EUA, as lojas de departamentos sediavam as reuniões das sufragistas ao mesmo tempo em que investiam em publicidade nas revistas do movimento. As militantes, à sua maneira, buscavam evidenciar suas feições e elegância feminina com vestidos longos e acessórios, sempre nas cores violeta, branca e verde para, de forma intencional, mostrar como tinham a dignidade da realeza, sua pureza e esperança por dias melhores para as mulheres (LE GOFF;AITKEN, 2011). Com isso, em via de mão dupla, eram as consumidoras das mesmas lojas de departamentos que as protegiam. A série $M r$. Selfridge (UK, 2013), da PBS, destaca a atenção do fundador da loja de departamentos inglesa Gordon Selfridge ao público feminino, e como se aliou, às sufragistas, ao permitir reuniões no café da loja, homenageá-las em suas vitrines e criar produtos nas cores que faziam alusão ao movimento. Os primeiros encontros do grupo em Londres foram realizados na loja. As militantes, muitas delas vindas das camadas mais altas da burguesia, foram capazes de fazer greves de fome, também partindo para táticas mais violentas com, até mesmo, o uso de bombas. Nesse contexto, a Selfridges abria as portas para o movimento, acompanhava os debates políticos e apoiava, financeiramente e com cartazes publicitários, as manifestações (LE GOFF; AITKEN, 2011). Essa parceria entre as sufragistas e a Selfridges foi abalada somente em 1912, quando militantes mais radicais tentaram apedrejar as vitrines da loja em protesto contra os salários irrisórios das funcionárias. De certa maneira, esse episódio de enfrentamento antecipa futuras tensões entre militantes feministas e o consumo, que ocorrem, no final da década de 1960, através das várias reorientações ideológicas do movimento. Apesar disso, entre meados do século XIX e início do XX, a aliança entre mulheres e grandes magazines foi um dos aspectos decisivos na ampliação da participação feminina na esfera pública. Nessa parceria de interesses comuns no âmbito das transformações modernas, a 
mulher tornou-se o centro do consumo nas lojas de departamentos, e ainda, por outro lado, fez uso desse grande comércio para fortalecer sua luta emancipatória.

\section{Considerações finais}

Mary Douglas e Baron Isherwood (2004) ensinaram que os bens são informação e, portanto, as atividades de consumo são uma modalidade central de comunicação na ordem da cultura. 0 consumo expressa simultaneamente dois movimentos opostos: por um lado, aproxima as pessoas através dos bens e, por outro, marca barreiras que diferenciam exatamente essas mesmas pessoas e bens. Trata-se de uma lógica fundamental no jogo de poderes e perigos nas relações sociais. A reciprocidade característica das práticas de consumo é uma forma de vínculo e, ao mesmo tempo, de separação para aqueles não habilitados a participar de determinadas transações.

Nesse artigo, analisamos três momentos históricos que demonstram a relação entre consumo e atuação política. Vimos como Elizabeth I e Luís XIV fizeram da moda, da etiqueta e das cerimônias de corte fatores de forçosa prodigalidade dos nobres, traduzida em um dispêndio capaz de corroer suas finanças e, com isso, o poder que dispunham. A coesão em torno do trono teve também, no consumo conspícuo, o sentido de força centrípeta e movimento estratégico. Os monarcas formularam hierarquias de distinção e prestígio por meio de severos códigos de consumo, que esvaziaram os espaços de uma aristocracia obrigada a gastar na corte a riqueza que, antes, sustentava seus poderes locais. Com esse artifício, consolidaram-se como centro dos sistemas político, econômico e social, ao transformar nobres em clientes. Diversos fatores podem ter contribuído para a longevidade de seus governos Elizabeth reinou por 45 anos e Luís por 72 - e para o destino absolutista de subordinação dos poderes locais a um centro de governo; o uso político do consumo foi, certamente, um deles.

O segundo momento trata da Revolução Americana e, particularmente, dos episódios de boicote aos produtos importados ingleses. Nesse caso, a sujeição das colônias ao Império Britânico se fazia também pelas condições impostas em transações comerciais. Assim, os colonos norte-americanos aprenderam que negar o consumo era uma forma efetiva de expressão política; não simples uma manifestação contra problemas pontuais, mas um processo simbólico capaz de gerar identidade cultural e desejo de autonomia do território. Refutar os bens ingleses passou, gradativamente, a significar liberdade para escolher os bens e pessoas com quem se conformar. 0 não consumo estabeleceu uma ponte entre os colonos e, no 
mesmo gesto, um muro a separar o outro imperial e opressor. Negar-se ao consumo dos bens importados se transformou em uma linguagem de aproximação e união das diferentes colônias em direção ao mesmo objetivo. 0 consumo, ou a recusa dele, contribuiu para formar um ideal patriótico comum, antes inexistente entre os grupos que povoavam o território dos Estados Unidos.

Por fim, na passagem do século XIX para o XX, vimos que a inserção da mulher como agente fundamental ao sistema de consumo representou uma etapa chave no longo e complexo processo de emancipação feminina. Os grandes magazines ofereceram uma opção de trabalho, um novo espaço de sociabilidade e um lugar de poder, onde mulheres circulavam independentes nas suas ações e seguras na expressão de seus propósitos. Eles foram uma alternativa para a inserção feminina na vida pública e fizeram do consumo um domínio por excelência das mulheres. Os movimentos políticos de organização das mulheres, sobretudo o sufragismo, em muito se beneficiaram dessa inusitada parceria e o consumo torna-se parte do próprio projeto de poder feminino. É evidente que muitas questões são suscitadas em relação à presença da figura feminina na publicidade, à associação desta às atividades de compras e às múltiplas opressões daí derivadas. Contudo, ao menos até as primeiras décadas do século $\mathrm{XX}$, os movimentos por direitos femininos e os grandes magazines convergiram interesses e, assim, pela via do consumo, as mulheres acessaram saberes e espaços antes restritos aos homens.

Deste modo, desde os primeiros momentos do processo de formação da modernidade, o consumo se inscreve como um fenômeno central. Seja como sistema classificatório, como modelador de sentidos para a cultura material ou como dispositivo de atribuição de identidades, o consumo é parte de um "espírito do tempo" há muito gestado - o nosso tempo presente. Suas representações e práticas viabilizaram projetos centralizadores de poder, construções da alteridade como ato revolucionário e parcerias imprevistas entre oprimidos e compras. 0 que surpreende, portanto, é encontrar o consumo em arranjos culturais que, muito além das complexidades socioeconômicas que tradicionalmente deflagra, o sustém como arena de atuação política e lugar de disputa pelo poder.

\section{Referências}

ARNAUD-DUC, Nicole. As contradições do Direito. In: FRAISSE, Geneviève; PERROT, Michelle. História das mulheres. Porto: Edições Afrontamento, 1991. 
Au bonheur des dames: l'invention du grand magasin. Direção de Christine LE GOFF e Sally AITKEN. França e Austrália: Arte France; Essential Media \& Entertainment; Planète; Special Broadcasting Service (SBS); Telfrance, 2011. Filme para televisão (85 min.).

BEAUVOIR, Simone. 0 segundo sexo 1: fatos e mitos. São Paulo: Difusão Européia do Livro, 1970.

BREEN, Timothy H. "Baubles of Britain": the American and consumer revolutions of the eighteenth century. Past and Present, Oxford, n. 119, p. 73-104, mai. 1988.

CAMPBELL. Colin. Ética romântica e o espirito do consumismo moderno. Rio de Janeiro: Rocco, 2001.

CANCLINI, Néstor Garcia. Consumidores e cidadãos. Rio de Janeiro: UFRJ, 2008.

DABHOIWALA, Faramerz. As origens do sexo: uma história da primeira revolução sexual. São Paulo: Biblioteca Azul, 2013.

DAMATTA, Roberto. Você tem cultura? In: DAMATTA, Roberto (org.). Ensaios de sociologia interpretativa. Rio de Janeiro: Rocco, 1986.

DARNTON, Robert. O Iluminismo como negócio. São Paulo: Cia das Letras, 1996.

DOUGLAS, Mary; ISHERWOOD, Baron. 0 mundo dos bens: por uma antropologia do consumo. Rio de Janeiro: UFRJ, 2004.

DRIVER, Stephanie. A declaração de independência dos Estados Unidos. Rio de Janeiro: Zahar, 2006.

ECO, Umberto. Apocalípticos e integrados. São Paulo: Perspectiva, 2008.

ELIAS, Norbert. A sociedade de corte. Rio de Janeiro: Zahar, 2001.

ENGELS, Friedrich. A situação da classe trabalhadora na Inglaterra. São Paulo: Boitempo, 2008.

FALCON, Francisco; RODRIGUES, Antonio Edmilson. A formação do mundo moderno: a construção do ocidente dos séculos XIV ao XVIII. Rio de Janeiro: Elsevier, 2006.

FRIEDLANDER, Larry. Friending the virgin: some thoughts on the prehistory of Facebook. SAGE Open, Londres, v. 1, n. 2, 2011.

FONTENELLE, Isleide. Consumo ético: construção de um novo fazer político? Revista Psicologia Política, São Paulo, v. 6, n.12, 2006.

GAY, Peter. Freud: uma vida para o nosso tempo. São Paulo: Companhia das Letras, 1989. 
GHILANI, Jessica. DeBeers' "Fighting diamonds": recruiting American consumers in World War II advertising. Journal of Communication Inquiry, Londres, v. 36, n. 3, p. 222-245, 2012.

JARDINE, Lisa. Worldly goods: a new history of the Renaissance. Nova lorque: W. W. Norton \& Company, 1998.

KROLOKKE, Charlotte; SCOTT, Anne. Three waves of feminism: from suffragettes to girls. In: Gender communication theories and analyses: from silence to performance. Thousand Oaks: SAGE, 2006.

LEACH, William. Transformations in a culture of consumption: women and department stores. The Journal of American History, Bloomington, v. 71, n. 2, 1984.

MACHADO, Mônica. Consumo e politização: discursos publicitários e novos engajamentos juvenis. Rio de Janeiro: Mauad, 2011.

MARX, Karl. O capital: crítica da economia política. Rio de Janeiro: Civilização Brasileira, 2008.

MAUSS, Marcel. Ensaio sobre a dádiva: forma e razão troca nas sociedades arcaicas. In: MAUSS, Marcel. Sociologia e Antropologia, vol. 2. São Paulo: EPU/EDUSP, 1974.

MCCRACKEN, Grant. Cultura e consumo: novas abordagens ao caráter simbólico dos bens e das atividades de consumo. Rio de Janeiro: Mauad, 2003.

MILL, John Stuart. The subjection of women. Nova lorque: Dover Publications, 1997.

MILLER, Michael B. The Bon Marché. New Jersey: Princeton University Press, 1981.

PORTILHO, Fátima. Consumo sustentável: limites e possibilidades de ambientalização e politização das práticas de consumo. CadernosEbape. br, Rio de Janeiro, v. 3, n. 3, p. 1-12, 2005.

PORTWOOD-STACER, Laura.Anti-consumption as tactical resistance: anarchists, subculture, and activist strategy. Journal of Consumer Culture, Londres, v. 12, n. 1, p. 87-105, 2012.

RICARDO, David. Princípios de economia política e tributação. São Paulo: Abril Cultural, 1982.

ROCHA, Everardo. Culpa e prazer: imagens do consumo na cultura de massa. Comunicação, Mídia e Consumo, São Paulo, v. 2, n. 3, p. 123-138, 2005.

ROCHA, Everardo; FRID, Marina; CORBO, William. Negócios e magias: Émile Zola, Au Bonheur des Dames e o consumo moderno. Comunicação, Mídia e Consumo, São Paulo, v.12, n.32, 2014.

SAHLINS, Marshall. Cultura e razão prática. Rio de Janeiro: Zahar, 1979.

SENNETT, Richard. O declínio do homem público. São Paulo: Companhia das Letras, 1988. 
STRONG, Roy. Splendor at court: renaissance spectacle and illusion. Londres: Weidenfeld and Nicolson, 1973.

SMITH, Adam. A riqueza das nações: investigação sobre sua natureza e suas causas. São Paulo: Abril Cultural, 1983.

WEBER, Max. A ética protestante e o espírito do capitalismo. São Paulo: Martin Claret, 2007.

WILLIAMS, Rosalind H. Dream worlds: mass consumption in late nineteenth century France. Berkeley, Los Angeles, Oxford: University of California, 1982.

ZOLA, Émile. O Paraíso das damas. São Paulo: Estação Liberdade, 2008.

\title{
Court, tea and vote: consumption as political arena
}

\begin{abstract}
This paper aims to investigate the mechanisms that articulate the phenomenon of consumption to the search for power and political activities on issues related to the symbolic character of goods, particular forms of commerce and new ways of sociability in shopping spaces. The work analyzes three historical experiences emblematic of the relationship between consumption and politics. The first deals with the court societies of Elizabeth I in England and Louis XIV in France; the second is the boycott known as Boston Tea Party during the American Revolution; the third examines the connection between department stores and the suffragist movement in the fight for women's rights in the early twentieth century. Therefore, this paper shows how some representations and practices of consumption take shape as arenas for political expression in the modern world
\end{abstract}

\section{Keywords}

Consumption and politics. Cultural history of consumption. Communication, power and consumption. Representations of consumption. Culture and consumption. 